This item was submitted to Loughborough's Research Repository by the author.

Items in Figshare are protected by copyright, with all rights reserved, unless otherwise indicated.

\title{
Novel octopus shaped organic-inorganic composite membranes for PEMFCs
}

PLEASE CITE THE PUBLISHED VERSION

http://dx.doi.org/10.1016/j.ijhydene.2016.05.078

\section{PUBLISHER}

(c) Hydrogen Energy Publications. Published by Elsevier

\section{VERSION}

NA (Not Applicable or Unknown)

\section{PUBLISHER STATEMENT}

This work is made available according to the conditions of the Creative Commons Attribution-NonCommercialNoDerivatives 4.0 International (CC BY-NC-ND 4.0) licence. Full details of this licence are available at: https://creativecommons.org/licenses/by-nc-nd/4.0/

\section{LICENCE}

CC BY-NC-ND 4.0

\section{REPOSITORY RECORD}

Liu, Qingting, Quan Sun, Na Ni, Fang Luo, Rong Zhang, Shengfei Hu, Xujin Bao, Fan Zhang, Feng Zhao, and Xiao Li. 2016. "Novel Octopus Shaped Organic-inorganic Composite Membranes for Pemfcs". figshare. https://hdl.handle.net/2134/21834. 


\title{
Novel Octopus Shaped Organic-Inorganic Composite Membranes for PEMFCs
}

\author{
Qingting Liu, ${ }^{\mathrm{a}, \mathrm{b}, \mathrm{c}^{*}}$, Quan Sun ${ }^{\mathrm{b}}$, Na Ni ${ }^{\mathrm{b}}$, Fang Luo ${ }^{\mathrm{b}}$, Rong Zhang ${ }^{\mathrm{a}, \mathrm{b}}$, Shengfei Hu${ }^{\mathrm{a}, \mathrm{b}}$, Xujin Bao ${ }^{\mathrm{c}}$, Fan \\ Zhang $^{\mathrm{c}}$, Feng Zhao ${ }^{\mathrm{d}}$ and Xiao $\mathrm{Li}^{\mathrm{d}}$ \\ ${ }^{a}$ Hubei Province Key Laboratory of Green Materials for Light Industry, Wuhan 430068, China \\ b School of Materials and Chemical Engineering, Hubei University of Technology, Wuhan \\ 430068, China \\ ${ }^{\text {c } D e p a r t m e n t ~ o f ~ M a t e r i a l s, ~ L o u g h b o r o u g h ~ U n i v e r s i t y, ~ L e i c e s t e r s h i r e ~ L E 11 ~ 3 N W, ~ U K ~}$ \\ ${ }^{\mathrm{d}}$ Wuhan Troowin Power System Technology Co. Ltd. Wuhan 430056, China \\ *liuqt@mail.hbut.edu.cn
}

\section{Abstract:}

Phosphoric acid doped polybenzimidazoles are among the most interesting proton exchange membrane materials for high temperature proton exchange membrane fuel cell applications. As a major challenge the proton conducting decline due to free phosphoric acid leaching during the long term fuel cell operation is addressed by fixing overmuch phosphoric acid in the polymer matrix. Novel organic-inorganic composite membranes are prepared via in situ synthesis of poly(2,5-benzimidazole) (ABPBI) and OctaAmmonium POSS (OA-POSS) hybrid composites (ABPBI/OA-POSS) following phosphoric acid doping and membrane casting procedures. Compared with the pristine ABPBI membrane, the introduction of OA-POSS into ABPBI polymer membrane caused water and phosphoric acid absorbilities increasing dramatically, resulting in the significant increase of proton 
conductivities at whether hydrous or anhydrous condition. ABPBI/3OA composite membranes with phosphoric acid uptake above 250\% showed best proton conductivities from room temperature to $160{ }^{\circ} \mathrm{C}$, indicating these composite membranes could be excellent candidates as a polymer electrolyte membrane for low and intermediate temperature applications.

Keywords: Poly(2,5-benzimidazole); OctaAmmonium POSS; phosphoric acid; proton conductivity; proton exchange membrane fuel cells

\section{Introduction}

As an energy conversion device, fuel cells have many advantages such as high efficiency, high power density, no charging requirement, easy cleaning, etc. [1,2] Among the family of fuel cells, polymer electrolyte membrane fuel cell (PEMFC) catalytically reacts with $\mathrm{H}_{2}$ and $\mathrm{O}_{2}$ to generate electricity with $\mathrm{H}_{2} \mathrm{O}$ as a byproduct and is regarded as the promising system as an environmentally friendly energy source $[3,4]$. In the PEMFC, the polymer electrolyte membrane (PEM) acts as a crucial role because it has to provide the proton pathway whilst keeps good mechanical properties all along the fuel cell operating life. Perfluorosulfonic acid (PFSA) membranes such as Nafion ${ }^{\circledR}$ from DuPont Company have been extensively studied and predominantly commercially used as PEMs due to their high initial performances and their good chemical stabilities. However, these features are limited by the strict temperature requirement (less than $100{ }^{\circ} \mathrm{C}$ ) [5,6]. Furthermore, PFSA membranes have been suffering aging phenomena during fuel cell working due to the irreversible loss of 
conductivity combined with membrane embrittlement and gas crossover $[4,7,8]$, which pose limitations in the PEMFC application. Therefore, it is essential to develop membrane materials with good electrical conductivity as well as high thermal and chemical stabilities at a relatively high temperature (e.g. above $100{ }^{\circ} \mathrm{C}$ ) that is not restricted by humid conditions.

Intermediate temperature proton exchange membrane fuel cells (IT-PEMFCs) which usually work between 100 and $200{ }^{\circ} \mathrm{C}$ get ever-increasing attention because of their many advantages, including faster electrochemical kinetics, improved and simplified water management, effective thermal management, improved CO tolerance etc. [9-11] However, the lack of suitable electrolyte materials that operate at the intermediate temperature range presents a great obstacle. Therefore, in the past few decades various systems have been developing to meet this challenge. Polybenzimidazoles (PBIs) have motivated extensive research activities with great progresses in recent years, because of their excellent chemical and thermal stabilities [12-15]. ABPBI [16] which is the simplest polybenzimidazole type polymer possessing comparable thermal and conducting properties as that of PBIs has also attracted the attention of many research groups in recent years [17-23]. However, the proton conductivities of polybenzimidazole membranes depend too much on the phosphoric acid doping percentages of membranes [24]. In addition, the mechanical properties and chemical stability of the acid-doped PBI membrane deteriorate rapidly due to seriously acid leaching under continuous usage [25]. To overcome the aforementioned drawbacks, the addition of modified inorganic/organic nanofillers to 
ABPBI matrix is regarded as an efficient approach [26-29].

Polyhedral oligosilsesquioxane (POSS) are silsequioxanes with a well-defined cube-octameric siloxane skeleton with eight organic vertex groups. These particular octahedral structural features render POSS to be a versatile additive for acquiring enhanced thermo-mechanical properties, better thermal stability, oxidative resistance and abrasion resistance [30,31]. Recently, the properties of Nafion/POSS composite membranes [32,33] and sulfonated poly(ether ether ketone)/POSS [30] have been reported. Due to the hygroscopic POSS cores and the functional groups from sulfonated POSS, the proton conductivity and mechanical properties have been greatly improved. Alli et al. [34] prepared composite membranes based on PBI and sulfonated POSS by solution casting as base materials for high temperature PEMFCs. After doping with PA, the composite membranes showed considerably improved ex situ proton conductivity under anhydrous as well as under fully humidified conditions in the $120-180{ }^{\circ} \mathrm{C}$ range which also benefit from functionalized POSS. Pan et al. [35] reported a new series of organic-inorganic cross-linked PEMs using sulfonated polyimides containing benzimidazole (SPIBIs) and glycidyl ether of POSS and achieved the proton conductivity up to $10^{-2} \mathrm{~S} \mathrm{~cm}^{-1}$ depending on the degree of sulfonation of the SPIBI.

We'd like to mention that, above development largely met PEMFCs' by requirement of working either at low temperature with fully hydrous or intermediate temperature with anhydrous and not for both low and intermediate temperature simultaneously. In this work, we selected OctaAmmonium POSS nanofillers [36]to 
modified ABPBI membrane through an in situ synthesis method as they have a large number of hydrophilic silicon-oxygen-silicon groups and base amino groups to severally stabilize $\mathrm{H}_{2} \mathrm{O}$ and $\mathrm{H}_{3} \mathrm{PO}_{4}$ molecules, which are very important for PEMFC to work from low temperature to intermediate temperature with hydrous and anhydrous conditions through different proton transfer mechanisms (so called “vehicle" mechanism under hydrous condition and "hopping” mechanism under anhydrous condition, respectively).

\section{Experimental}

\subsection{Polymer Synthesis}

ABPBI monomer 3,4-diaminobenzoic acid (DABA, 97\%) was purchased from Beijing J\&K Technology CO., Ltd. OctaAmmonium POSS (AM-POSS, trade name AM0285) was obtained from Hybrid Plastics Inc. Phosphorus pentoxide $\left(\mathrm{P}_{2} \mathrm{O}_{5}\right)$ and methane sulfonic acid (MSA, 99\%) were obtained from Sinopharm Chemical Reagent CO., Ltd. and Aladdin Industrial Corporation, respectively. All chemicals and solvents were used as received without any further purification steps.

Synthesis of ABPBI/AM-POSS composites: $0.03 \mathrm{~g}$ of AM-POSS and $10 \mathrm{~mL}$ of MSA were added into a $100 \mathrm{~mL}$ three-neck flask and ultrasonicated at atmosphere for 30 minutes to obtain a milky white homogeneous solution. Then $1.0 \mathrm{~g}$ of DABA and $1.5 \mathrm{~g}$ of $\mathrm{P}_{2} \mathrm{O}_{5}$ were added following another 30 minutes of ultrasonication treatment. Subsequently, the mixtures were heated under $\mathrm{N}_{2}$ atmosphere with a magnetic stirrer up to $100{ }^{\circ} \mathrm{C}$ and kept for 30 minutes, then continuously heated up to $150{ }^{\circ} \mathrm{C}$ and kept 
for about 2 hours. The hot polymer solution was slowly poured into the deionized water $(500 \mathrm{~mL})$ to get very thin fibers. The obtained fibers were boiled in a beaker with $500 \mathrm{~mL} 10 \% \mathrm{NaOH}$ solution at $100{ }^{\circ} \mathrm{C}$ for 2 hour to remove phosphoric acid and the solvent, subsequently boiled in $500 \mathrm{~mL}$ deionized water for 1 hour to remove $\mathrm{NaOH}$. After that, the fibers were washed with deionized water for several times to remove residual $\mathrm{NaOH}$. Finally, the fibers were dried in a vacuum oven at $110{ }^{\circ} \mathrm{C}$ for 24 hours. The obtained dark brown fibers were placed in a sealed flask.

Synthesis of $A B P B I$ : ABPBI polymer as a reference was synthesized in $M S A / \mathrm{P}_{2} \mathrm{O}_{5}$ media according to Kim et al.’s report. [17] The purification and dryness procedures were same as these of above ABPBI/AM-POSS composites.

\subsection{Membrane preparation}

ABPBI/AM-POSS composite membranes: $0.4 \mathrm{~g}$ of ABPBI/AM-POSS powder was dissolved in $6.0 \mathrm{~mL}$ of MSA with magnetic stirring overnight at room temperature to obtain a homogeneous solution. Then the viscous solution was cast onto a flat bottom Petri dish and solvent was removed by step by step heating in a ventilated oven up to $200{ }^{\circ} \mathrm{C}$ to avoid pin holes caused by rapid evaporation of MSA. After that the Petri dish was cooled down to $100{ }^{\circ} \mathrm{C}$ and hot water poured onto it to peel off the membrane. The membrane was then dried in a vacuum oven at $110{ }^{\circ} \mathrm{C}$ for 24 hours. Finally the obtained dried membrane was carefully stored to avoid moisture absorption before characterizations.

PA doped ABPBI/AM-POSS composite membranes: to achieve membranes with 
various PA doping levels, 2 to 12 M PA solutions were prepared. Phosphoric acid doping was carried out by immersing a weighted dry membrane (area about $3 \mathrm{~cm} \times 3$ $\mathrm{cm}$ ) in a specified concentration of PA solution for 3 days at room temperature till the weight of the wet membrane reached an equilibrium value. Then the PA doped membrane was rinsed with plenty of deionized water to remove free phosphoric acid on the membrane surface then dried in a vacuum oven at $110{ }^{\circ} \mathrm{C}$ for 24 hours.

\subsection{Membrane characterization}

Morphological characterization. The morphologies and distribution of silicon element of membranes were studied with a Scanning Electron Microscopy coupled with Energy Dispersive X-ray Spectroscopy (SEM-EDS, JSM-5610LV, JEOL Ltd., Japan). For SEM-EDS test, the samples were coated with gold plate before SEM observations were carried out.

Fourier transform infrared (FT-IR) spectroscopy. FT-IR spectra of the composite were recorded on a Nicolet 6700 spectrometer (Thermo Fisher Scientific, USA) with a resolution of $4 \mathrm{~cm}^{-1}$ and 64 scans in the region of $4000-400 \mathrm{~cm}^{-1}$.

Thermal characterization. A simultaneous TGA/DSC (2960 SDT V3.0F, TA Instruments Inc., USA) was used to trace the thermostabilities of the polymeric membranes. The samples were examined in a nitrogen atmosphere from room temperature to $900{ }^{\circ} \mathrm{C}$ with a heated rate of $10^{\circ} \mathrm{C} \mathrm{min}^{-1}$.

Water uptake and PA doping level measurements. The undoped (no PA doped) pristine ABPBI membranes and ABPBI/AM POSS composite membranes (area about 
$3 \mathrm{~cm} \times 3 \mathrm{~cm}$ ) were soaked in ionized water at $25{ }^{\circ} \mathrm{C}$ for 8 hours and their values of water uptake were obtained by calculating the percentage of weight gain with respect to the dried membrane weight. The PA doping level of a membrane was defined as the phosphoric acid molecule per repeat unit of ABPBI polymer. The PA doping levels of ABPBI membranes and ABPBI/AM POSS composite membranes were measured according to the weight changes before and after doping. The water uptake and PA doping level were calculated as shown in reference [37].

Proton conductivity measurement. A Solartron Analytical 1280 Electrochemical Measurement unit (1280 EMU, Solartron Analytical Ltd., UK) with an environmental test chamber (LP-80U, Guangdong Hongzhan Tech, China) was used to measure the impedance of membranes at different temperatures and anhydrous atmosphere (very low humidity). A two-probe mode with a $10 \mathrm{mV}$ perturbation potential was used. The proton conductivity $(\sigma)$ of an electrochemical cell can be calculated according to the reference [38].

\section{Results and discussion}

\subsection{Morphology Characterization}
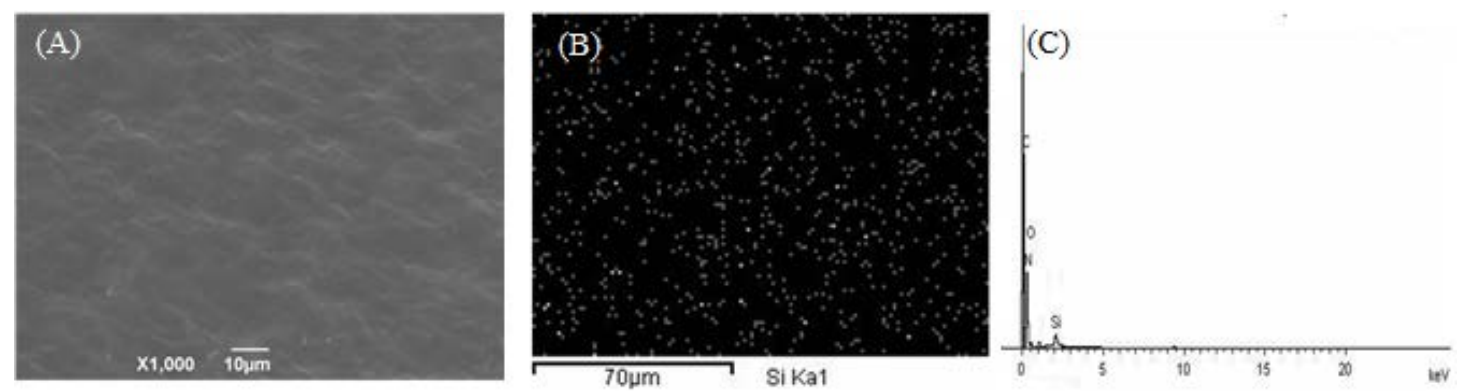

Fig. 1 SEM-EDS results of ABPBI/AM-POSS composite membrane: (A) image of membrane morphology, (B) image of Si distribution and (C) elemental analysis of membrane 
Fig. 1 showed SEM-EDS results of the ABPBI/AM-POSS composite membrane. The surface appearance of Fig. 1(A) showed that the relatively flat membrane was obtained whilst (B) and (C) indicated that AM-POSS particles dispersed uniformly in the polymer matrix. Furthermore, in Fig. 1(C), the absence of $S$ also indicates that the residual MSA have been completely moved through boiling and rinsing processes which are given in above sections (2.1 and 2.2).

\subsection{Structure analysis}

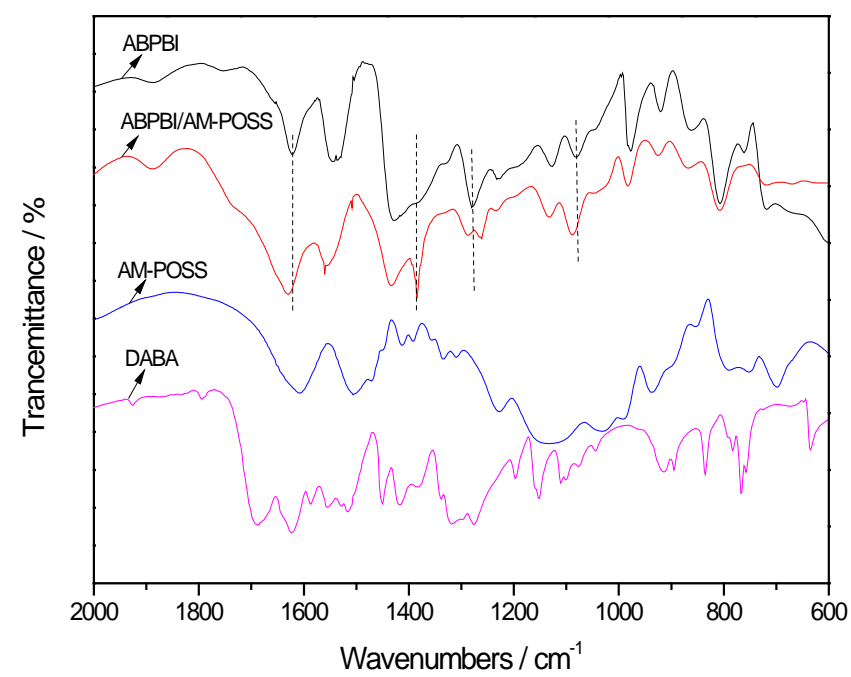

Fig. 2 FTIR spectra of ABPBI and ABPBI/AM-POSS composite

In the spectrum of ABPBI polymer (Fig. 2), the typical characteristic of benzimidazole ring appears at 1622, 1541, 1280, 1128, 984, 922, 849, 810, 762 and $721 \mathrm{~cm}^{-1}$. Compared with the spectrum of ABPBI, in the spectrum of ABPBI/AM-POSS composites, the typical characteristic of benzimidazole ring is clearly appeared. Besides, the enhancement of absorption at $1089 \mathrm{~cm}^{-1}$ is due to the overlap of the broad peak from $1200-1000 \mathrm{~cm}^{-1}$ which is the characteristic of 
AM-POSS cage and network; the breathing mode of the imidazole ring at $1286 \mathrm{~cm}^{-1}$ which is drifted compared with the wave number of $1280 \mathrm{~cm}^{-1}$ in the spectra of ABPBI should be resulted by the effects of grafted POSS cages; the peaks at 1263 and $1384 \mathrm{~cm}^{-1}$ which are the characteristic of the stretching mode of $\mathrm{N}-\mathrm{H}$ and $\mathrm{C}-\mathrm{N}$ in the amide group, whilst the greatly enhanced absorption peak at $1631 \mathrm{~cm}^{-1}$ is overlapped by the vibration of symmetric $\mathrm{C}=\mathrm{O}$ in the amide group [38]. The suggested chemical reactions are shown in Fig. 3. At $100{ }^{\circ} \mathrm{C}$, the amidation reaction between the amino groups from AM-POSS and carboxyl groups from DABA monomer occurred; with the temperature increasing to $150{ }^{\circ} \mathrm{C}$, the amino groups and the carboxyl groups from the DABA condensed into imidazole groups and finally the novel octopus shaped organic-inorganic composite structures were formed.
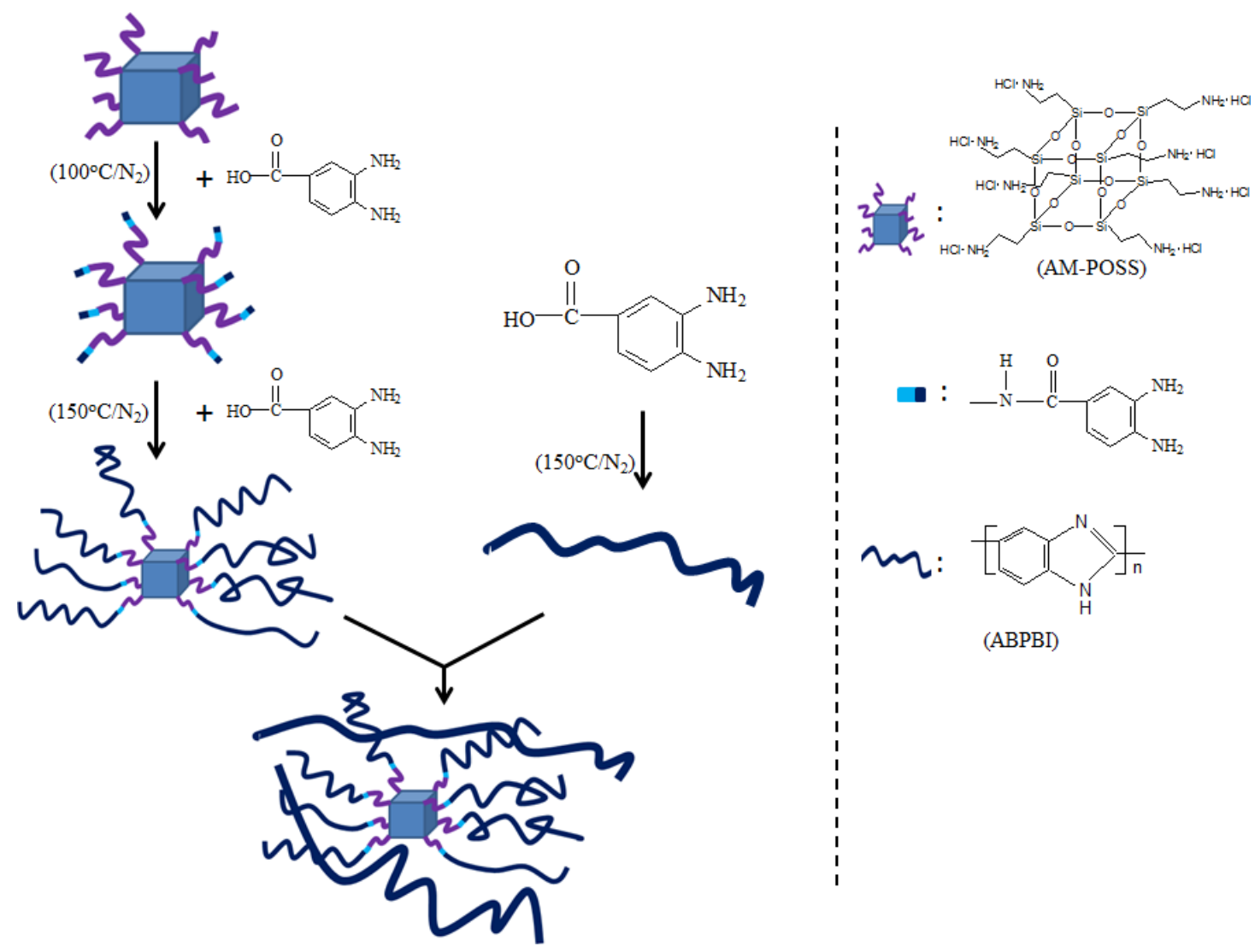

Fig. 3 Octopus shaped structure of ABPBI/AM-POSS 


\subsection{Thermal stability}

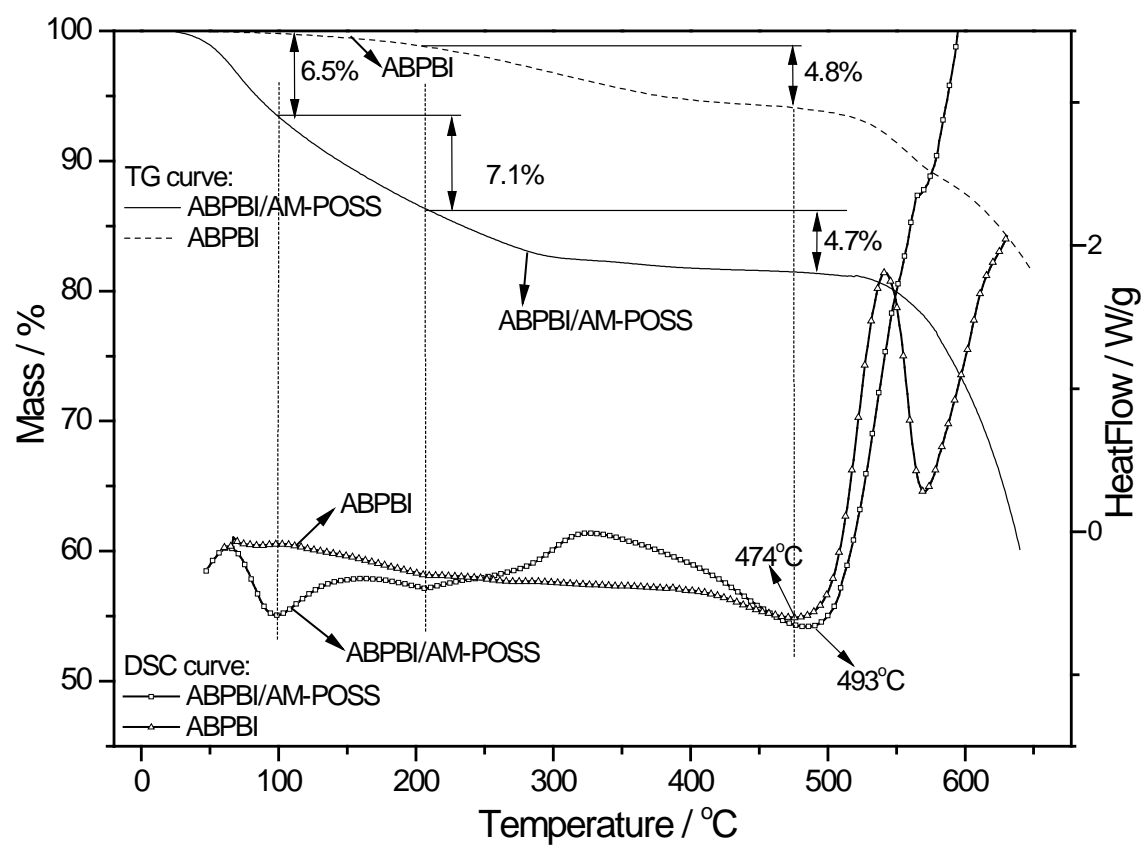

Fig. 4 TGA/DSC curves of ABPBI and ABPBI/AM-POSS composites

The TGA and DSC curves of ABPBI and ABPBI/AM-POSS composites are shown in Fig. 4, respectively. In the TG curve of ABPBI, less than $1.2 \%$ of the weight loss before $200{ }^{\circ} \mathrm{C}$ is due to the volatilization of free and hydrogen bonded water [24] and around $4.8 \%$ of weight loss is addressed to the volatilization and thermal oxidation decomposition of oligomers of ABPBI, then after $474{ }^{\circ} \mathrm{C}$ the continuous weight loss is attributed by the oxidative decomposition of end groups in ABPBI backbones then complete decomposition of ABPBI backbones. The related DSC curve also showed the thermal variation during the whole weight loss. In the TG curve of ABPBI/AM-POSS, the $6.5 \%$ of weight loss before $100{ }^{\circ} \mathrm{C}$ and $7.1 \%$ of weight loss between 100 and $200{ }^{\circ} \mathrm{C}$ are due to the volatilization of free and hydrogen bonded water, respectively. These results also indicated the composites have better 
abilities of water absorption and retention (the content of hydrogen bonded water equates to the ability of water retention). The $4.7 \%$ amount of weight loss between 200 and $493{ }^{\circ} \mathrm{C}$ is also addressed to the leave of oligomers of ABPBI. Whilst the complete decomposition of composites are observed after occurred after $493{ }^{\circ} \mathrm{C}$, which suggests the composites have better thermostability since most of the end carboxyl groups have chemically reacted into amide groups.

\subsection{Absorbilities of water and phosphoric acid}

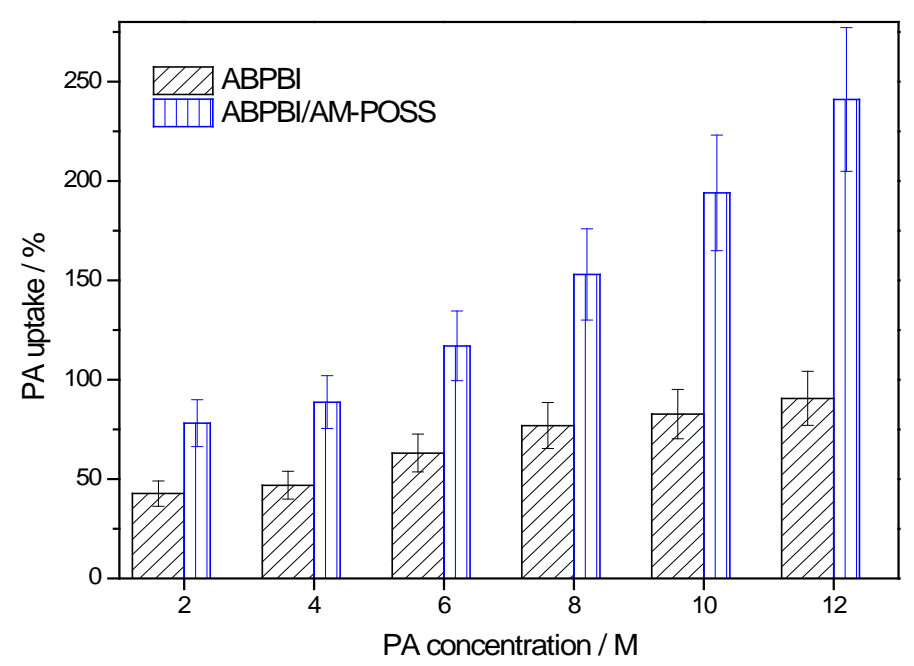

Fig. 5 Phosphoric acid uptake of ABPBI and ABPBI/AM-POSS composites

The values of PA uptake of ABPBI and ABPBI/AM-POSS composite membrane are shown in Fig. 5. With the increase of PA concentrations from 2 to $12 \mathrm{M}$, PA uptake of $\mathrm{ABPBI}$ and $\mathrm{ABPBI} / \mathrm{AM}-\mathrm{POSS}$ both increase and increasing rate of PA uptake for ABPBI/AM-POSS composites is higher than that of ABPBI. For ABPBI polymer, the increase of PA uptake is mainly due to the basic imidazole groups absorbing PA. Meanwhile, for ABPBI/AM-POSS, besides the basic imidazole groups, the basic 
amide groups which bridge ABPBI and AM-POSS can ionically link PA and hydrophilic POSS core can absorb $\mathrm{H}_{3} \mathrm{PO}_{4}$ via hydrogen bond, therefore resulting in the faster increase of PA uptake.

Table 1 Water uptake of $\mathrm{H}_{3} \mathrm{PO}_{4}$ doped ABPBI and ABPBI/AM-POSS membranes

\begin{tabular}{lcc}
\hline \multirow{2}{*}{ Membrane } & \multicolumn{2}{c}{ Water uptake, \% } \\
\cline { 2 - 3 } & Saturated & Ambient atmosphere \\
\hline ABPBI & $31.6 \pm 1.6$ & $23.2 \pm 1.1$ \\
ABPBI-60PA & $34.7 \pm 3.5$ & $13.7 \pm 0.4$ \\
ABPBI-84PA & $53.0 \pm 5.3$ & $15.0 \pm 0.5$ \\
ABPBI/AM-POSS & $106.2 \pm 5.3$ & $32.3 \pm 1.6$ \\
ABPBI/AM-POSS-88PA & $108.0 \pm 5.5$ & $36.1 \pm 0.7$ \\
ABPBI/AM-POSS-153PA & $133.2 \pm 6.5$ & $47.8 \pm 1.0$ \\
ABPBI/AM-POSS-241PA & $153.6 \pm 7.5$ & $58.2 \pm 1.2$ \\
\hline
\end{tabular}

The water uptake of $\mathrm{H}_{3} \mathrm{PO}_{4}$ doped ABPBI and ABPBI/AM-POSS composite membranes are given in Table 1 . It can be seen that the water absorbility of $\mathrm{H}_{3} \mathrm{PO}_{4}$ doped ABPBI and ABPBI/AM-POSS composite membranes was enhanced with the increased $\mathrm{H}_{3} \mathrm{PO}_{4}$ uptakes either at a saturated condition or ambient atmosphere. This is due to the hydrogen bonds formed between $\mathrm{H}_{3} \mathrm{PO}_{4}$ and water molecules i.e. $(\mathrm{HO})_{2} \mathrm{OP}-\mathrm{OH} \cdots \mathrm{OH}_{2}$ or $(\mathrm{HO})_{3} \mathrm{P}=\mathrm{O} \cdots \mathrm{H}-\mathrm{O}-\mathrm{H}$. The water uptake of ABPBI/AM-POSS was significant higher than ABPBI membrane even without phosphoric acid doping, indicating the dominant contribution of water uptake must result from the embedded AM-POSS particles. 


\subsection{Proton conductivity}

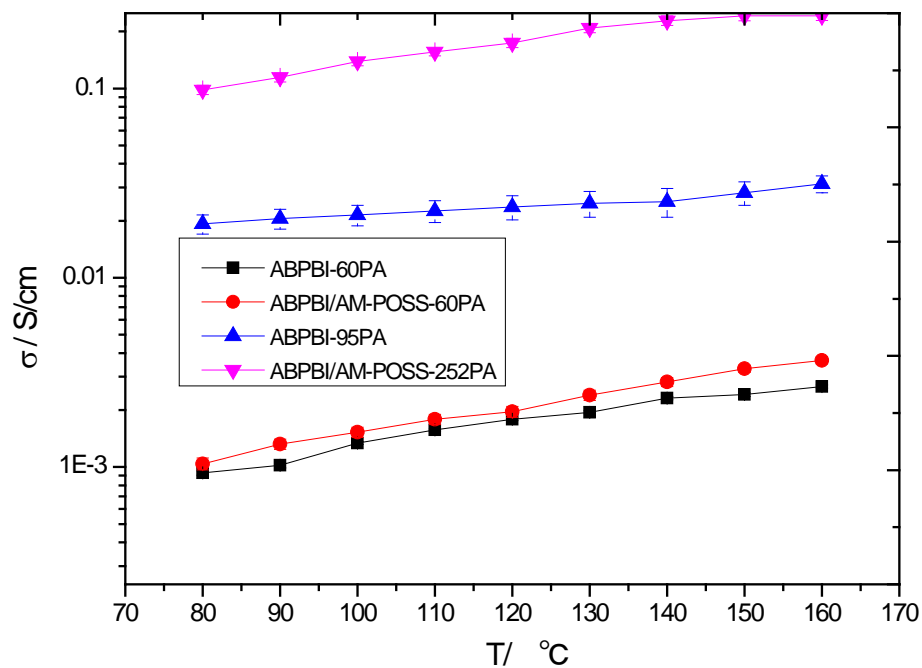

Fig. 6 Proton conductivity of $\mathrm{H}_{3} \mathrm{PO}_{4}$ doped ABPBI and ABPBI/AM-POSS composite membranes at anhydrous atmosphere

In Fig. 6, the proton conductivities of PA doped ABPBI and ABPBI/AM-POSS composite membranes increased with the elevated temperatures and PA doping levels. When with the same PA doping levels (i.e. 60\% PA uptake), the proton conductivities of ABPBI/AM-POSS composites were slightly higher than these of PA doped pristine ABPBI membranes. Generally, at the anhydrous atmosphere the proton conducting mainly relies on the PA molecules, in other words, same PA doping level should achieve similar proton conductivity. Therefore, the higher conductivity from composite membrane should be attributed by the hydrogen bonded water which is confirmed through TGA/DSC results. With the increase of PA amount, the proton conductivities increase dramatically because more PA molecules can provide more proton conducting routes, therefore resulting higher proton conductivities. It's worth noting that the composite membrane with $250 \%$ PA uptake has very good proton 
conductivities (above $0.1 \mathrm{~S} \mathrm{~cm}^{-1}$ ) even at low temperature range (below $100{ }^{\circ} \mathrm{C}$ ), which shows these composite membranes have the potential to run at a broad temperature without humidity requirement.

\section{Conclusion}

ABPBI/AM-POSS composite membranes with unique chemical structures were successfully prepared via in-situ synthesis followed by membrane casting. The octopus shaped structure of ABPBI polymer grafted into AM-POSS cores enhances the polymer's thermostability and the introduction of AM-POSS significantly increases the absorbilities of water and phosphoric acid, which is particularly important for PEMFC running at a very wide temperature range and without humidity requirement. The competitive proton conductivities at the temperature range of 80 to $160{ }^{\circ} \mathrm{C}$ from ABPBI/AM-POSS composite membranes with high phosphoric acid doping levels indicates that they are very good candidates for applying in PEMFCs.

\section{Acknowledgment}

The authors wish to acknowledge financial support provided by the Hubei Provincial Key Technology R\&D Program (Grant no. [2013]2-3), Science and Technology Department of Hubei Province (Grant no. 2013BAA086)and the Human Resource and Social Security Ministry for Returned Chinese Scholars, China (Grant no. [2014]240). 


\section{References}

[1] R. O' Hayre, S.W. Cha, W. Colella, F.B. Prinz, Fuel Cell Fundamentals. New Jersey : John Wiley \& Sons; 2005.

[2] J. Larminie, A. Dicks, Fuel Cell Systems Explained, 2nd edition. England: John Wiley \& Sons; 2003.

[3] M. Doyle, G. Rajendran, Perfluorinated Membranes in Handbook of Fuel Cells: Fundamentals, Technology and Applications, in: W. Vielstich, A. Lamm, H.A. Gasteiger (Eds.) Handbook of Fuel Cells: Fundamentals, Technology, Applications. Chichester, England: John Wiley \& Sons; 2003: 351-395.

[4] Z. Qi, Proton Exchange Membrane Fuel Cells. CRC Press; 2013.

[5] K.D. Kreuer, Fast proton conductivity: A phenomenon between the solid and the liquid state. Solid State Ionics 1997;94:55-62.

[6] Q.F. Li, R.H. He, J.O. Jensen, N.J. Bjerrum, Approaches and recent development of polymer electrolyte membranes for fuel cells operating above 100 degrees C. Chem. Mater. 2003;15:4896-4915.

[7] W. Liu, K. Ruth, G. Rusch, Membrane durability in PEM fuel cells. J. New Mater. Electrochem. Syst. 2001;4:227-232.

[8] M. Rikukawa, K. Sanui, Proton-conducting polymer electrolyte membranes based on hydrocarbon polymers. Prog. Polym. Sci. 2000;25:1463-1502.

[9] J. Zhang, Z. Xie, J. Zhang, Y. Tang, C. Song, T. Navessin, et al. Holdcroft, High temperature PEM fuel cells. J. Power Sources 2006;160:872-891.

[10] A. Verma, K. Scott, Development of high-temperature PEMFC based on heteropolyacids and polybenzimidazole, J.Solid State Electrochem. 2008;14:213-219. 
[11] G. Alberti, M. Casciola, Composite membranes for medium-temperature PEM fuel cells. Annu. Rev. Mater. Res. 2003;33:129-154.

[12] B.Z. Xing, O. Savadogo, The effect of acid doping on the conductivity of polybenzimidazole (PBI). J. New Mater. Electrochem. Syst. 1999;2:95-101.

[13] F. Mack, S. Heissler, R. Laukenmann, R. Zeis, Phosphoric acid distribution and its impact on the performance of polybenzimidazole membranes. J. Power Sources 2014;270:627-633.

[14] G.A. Serad, Polybenzimidazoles, new thermally stable polymers - Comments. J. Polym. Sci., Part A: Polym. Chem. 1996;34:1123-1124.

[15] M. Malinowski, A. Iwan, Electrochemical properties of PEM fuel cells based on Nafion-polybenzimidazole-imidazole hybrid membranes. Int. J. Hydrogen Energy 2015;40:833-840.

[16] J.A. Asensio, S. Borros, P. Gomez-Romero, Proton-conducting polymers based on benzimidazoles and sulfonated benzimidazoles. J. Polym. Sci., Part A: Polym. Chem. 2002;40:3703-3710.

[17] H.-J. Kim, S.Y. Cho, S.J. An, Y.C. Eun, J.-Y. Kim, H.-K. Yoon, H.-J. Kweon, K.H. Yew, Synthesis of Poly(2,5-benzimidazole) for Use as a Fuel-Cell Membrane. Macromol. Rapid Commun. 2004;25:894-897.

[18] J.A. Asensio, S. Borrós, P. Gómez-Romero, Sulfonated poly(2,5-benzimidazole) (SABPBI) impregnated with phosphoric acid as proton conducting membranes for polymer electrolyte fuel cells. Electrochim. Acta 2004;49:4461-4466.

[19] L.A. Diaz, G.C. Abuin, H.R. Corti, Water and phosphoric acid uptake of poly [2,5-benzimidazole] (ABPBI) membranes prepared by low and high temperature casting. J. Power Sources 2009;188:45-50.

[20] S.-K. Kim, T.-H. Kim, T. Ko, J.-C. Lee, Cross-linked poly(2,5-benzimidazole) consisting of wholly aromatic groups for high-temperature PEM fuel cell applications. J. Membr. Sci. 
2011;373:80-88.

[21] J.A. Asensio, S. Borrós, P. Gómez-Romero, Polymer Electrolyte Fuel Cells Based on Phosphoric Acid-Impregnated Poly(2,5-benzimidazole) Membranes. J. Electrochem. Soc. 2004;151:A304.

[22] F.L. Dong, Z.F. Li, S.W. Wang, Z.H. Wang, Synthesis and characteristics of proton-conducting membranes based on cerium sulfophenyl phosphate and poly (2,5-benzimidazole) by hot-pressing method. Int. J. Hydrogen Energy 2011;36:11068-11074.

[23] H. Sun, J.J. Zuo, X. Wang, Y. Wan, Proton transfer reaction in poly (2,5-polybenzimidazole) doping with $\mathrm{H}_{3} \mathrm{PO}_{4}$. Int. J. Hydrogen Energy 2014;39:13808-13815.

[24] J. Cho, J. Blackwell, S.N. Chvalun, M. Litt, Y. Wang, Structure of a poly(2,5-benzimidazole)/phosphoric acid complex. J. Polym. Sci., Part B: Polym. Phys. 2004;42:2576-2585.

[25] F.J. Nores-Pondal, M.P. Buera, H.R. Corti, Thermal properties of phosphoric acid-doped polybenzimidazole membranes in water and methanol-water mixtures. J. Power Sources 2010;195:6389-6397.

[26] M. Linlin, A.K. Mishra, N.H. Kim, J.H. Lee, Poly(2,5-benzimidazole)-silica nanocomposite membranes for high temperature proton exchange membrane fuel cell. J. Membr. Sci. 2012;411-412:91-98.

[27] A.K. Mishra, N.H. Kim, J.H. Lee, Effects of ionic liquid-functionalized mesoporous silica on the proton conductivity of acid-doped poly(2,5-benzimidazole) composite membranes for high-temperature fuel cells. J. Membr. Sci. 2014;449:136-145.

[28] D. Aili, T. Allward, S.M. Alfaro, C. Hartmann-Thompson, T. Steenberg, H.A. Hjuler, et al. Polybenzimidazole and sulfonated polyhedral oligosilsesquioxane composite membranes for high 
temperature polymer electrolyte membrane fuel cells. Electrochim. Acta 2014;140:182-190.

[29] W. Qian, Y. M. Shang, S. B. Wang, X. F. Xie, Z. Q. Mao. Phosphoric acid doped composite membranes from poly (2,5-benzimidazole) (ABPBI) and $\mathrm{CsxH}_{3} \mathrm{LxPW}_{12} \mathrm{O}_{40} / \mathrm{CeO}_{2}$ for the high temperature PEMFC. Int. J. Hydrogen Energy 2013;38:11053-11059.

[30] D. Gupta, A. Madhukar, V. Choudhary, Effect of functionality of polyhedral oligomeric silsesquioxane [POSS] on the properties of sulfonated poly(ether ether ketone) [SPEEK] based hybrid nanocomposite proton exchange membranes for fuel cell applications. Int. J. Hydrogen Energy 2013;38:12817-12829.

[31] S.K. Yadav, S.S. Mahapatra, H.J. Ryu, H.J. Yoo, J.W. Cho, Synthesis of high performance organic-inorganic composite via click coupling of block polymer and polyhedral oligomeric silsesquioxane. React. Funct. Polym. 2014;81:91-96.

[32] S. Subianto, M.K. Mistry, N.R. Choudhury, N.K. Dutta, R. Knott, Composite polymer electrolyte containing ionic liquid and functionalized polyhedral oligomeric silsesquioxanes for anhydrous PEM applications. Acs Appl. Mater. Inter. 2009;1:1173-1182.

[33] C. del Río, E. Morales, P.G. Escribano, Nafion/sPOSS hybrid membranes for PEMFC. Single cell performance and electrochemical characterization at different humidity conditions. Int. J. Hydrogen Energy 2014;39:5326-5337.

[34] D. Aili, T. Allward, S.M. Alfaro, C. Hartmann-Thompson, T. Steenberg, H.A. Hjuler, Q.F. Li, J.O. Jensen, E.J. Stark, Polybenzimidazole and sulfonated polyhedral oligosilsesquioxane composite membranes for high temperature polymer electrolyte membrane fuel cells. Electrochim. Acta 2014;140:182-190.

[35] H. Pan, Y. Zhang, H. Pu, Z. Chang, Organic-inorganic hybrid proton exchange membrane based 
on polyhedral oligomeric silsesquioxanes and sulfonated polyimides containing benzimidazole. J. Power Sources 2014;263:195-202.

[36] Y. Zhang, S. Lee, M. Yoonessi, K. Liang, C.U. Pittman, Phenolic resin-trisilanolphenyl polyhedral oligomeric silsesquioxane (POSS) hybrid nanocomposites: Structure and properties. Polymer 2006;47:2984-2996.

[37] O. Acar, U. Sen, A. Bozkurt, A. Ata, Proton conducting membranes based on Poly(2,5-benzimidazole) (ABPBI)-Poly(vinylphosphonic acid) blends for fuel cells, Int. J. Hydrogen Energy 2009;34:2724-2730.

[38] Z. Wu, S. Zhang, H. Li, Y. Liang, Z. Qi, Y. Xu, Y. Tang, C. Gong, Linear sulfonated polyimides containing polyhedral oligomeric silsesquioxane (POSS) in main chain for proton exchange membranes. J. Power Sources 2015;290:42-52. 
Fig. 1

SEM-EDS results of ABPBI/AM-POSS composite membrane: (A) image of membrane morphology, (B) images of Si distribution and (C) elemental analysis of membrane
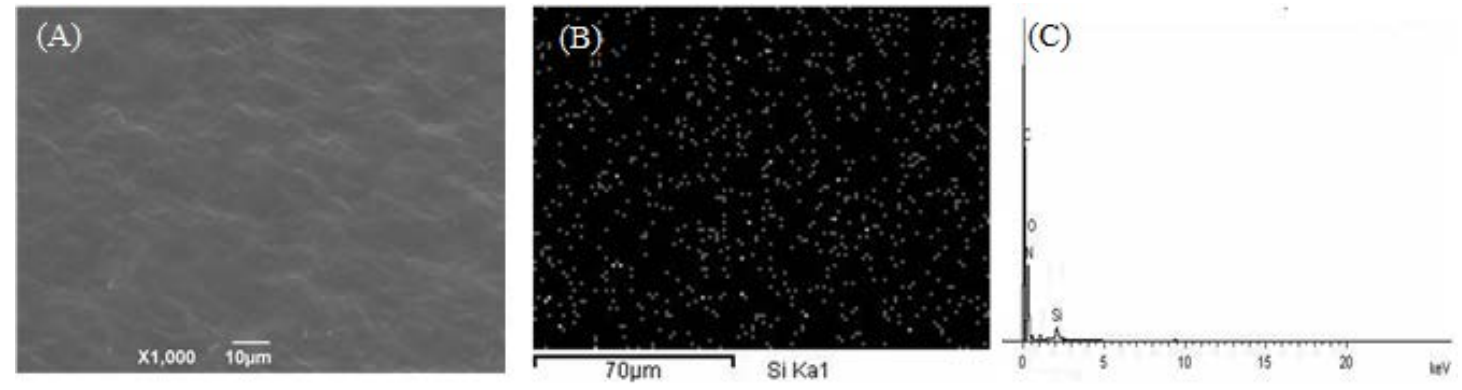
Fig. 2

FTIR spectra of ABPBI and ABPBI/AM-POSS composite

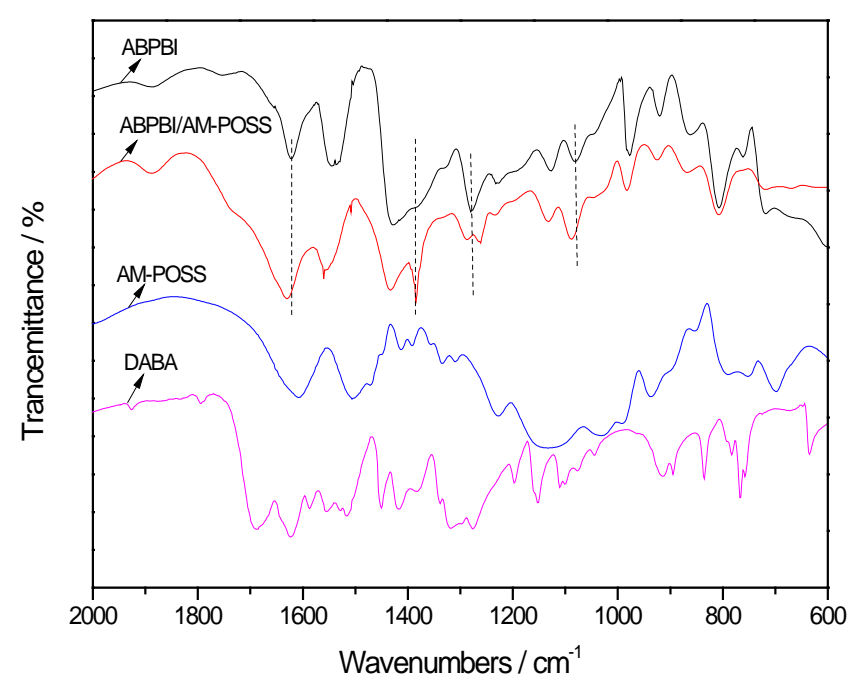


Fig. 3

Octopus shaped structure of ABPBI/AM-POSS

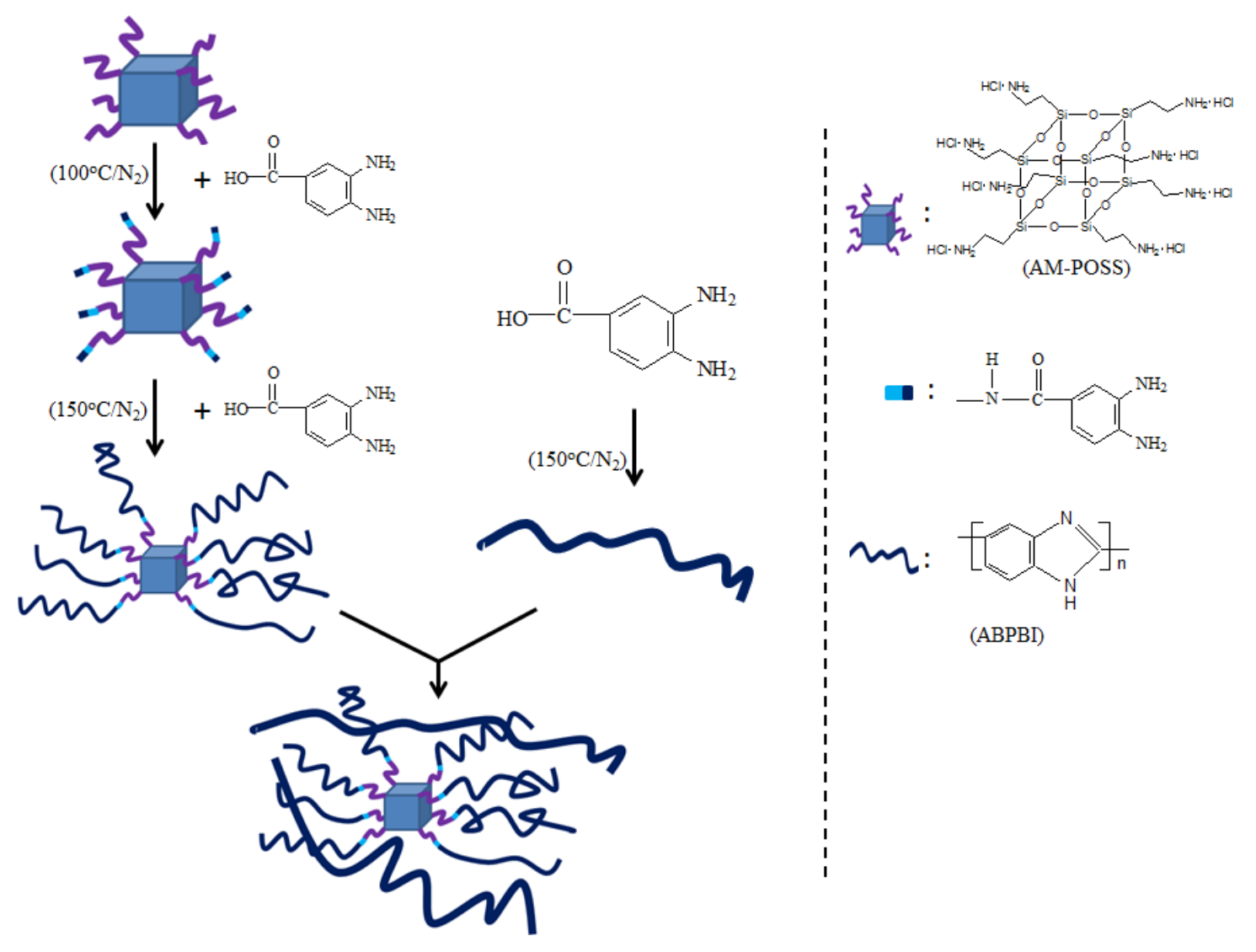


Fig. 4

TGA/DSC curves of ABPBI and ABPBI/AM-POSS composites

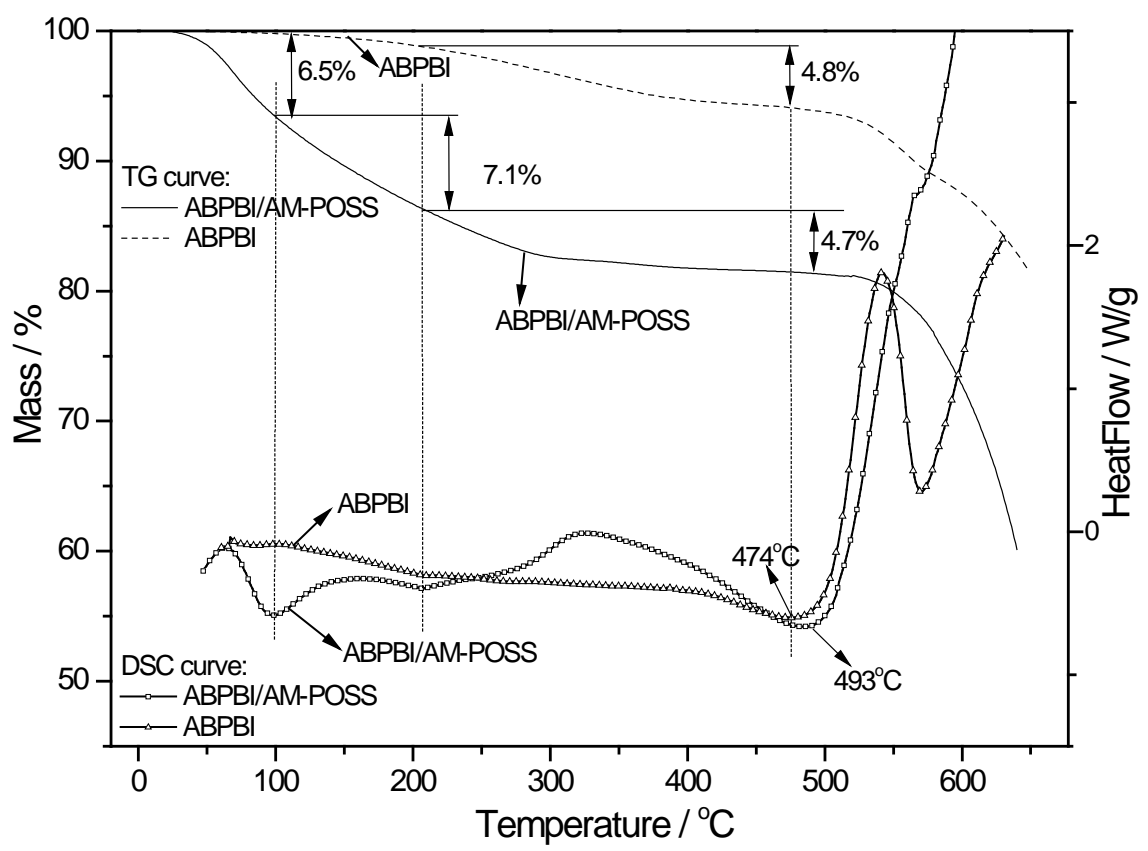


Fig. 5

Phosphoric acid uptake of ABPBI and ABPBI/AM-POSS composites

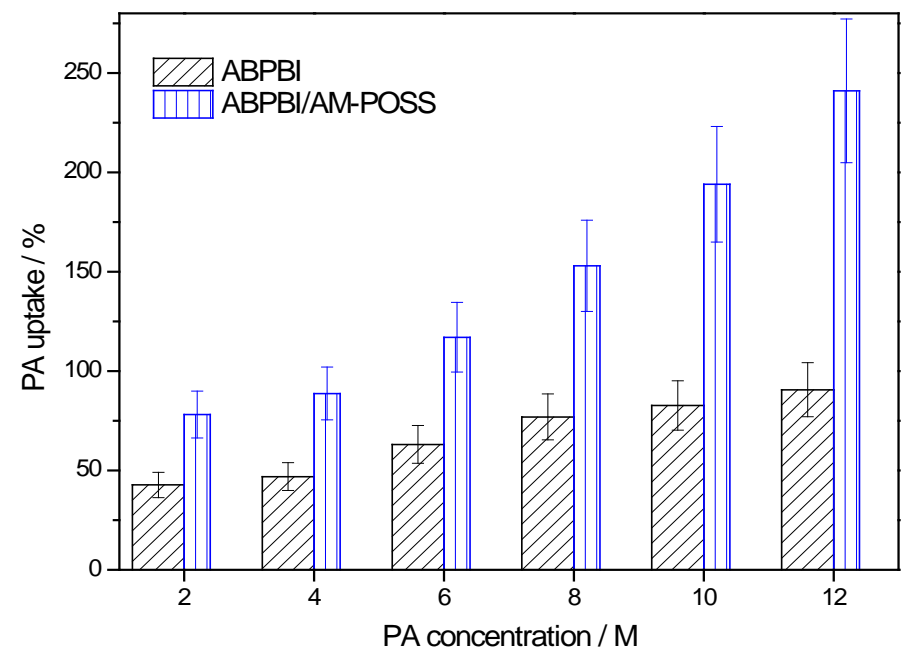


Fig. 6

Proton conductivity of $\mathrm{H}_{3} \mathrm{PO}_{4}$ doped ABPBI and ABPBI/AM-POSS composite membranes

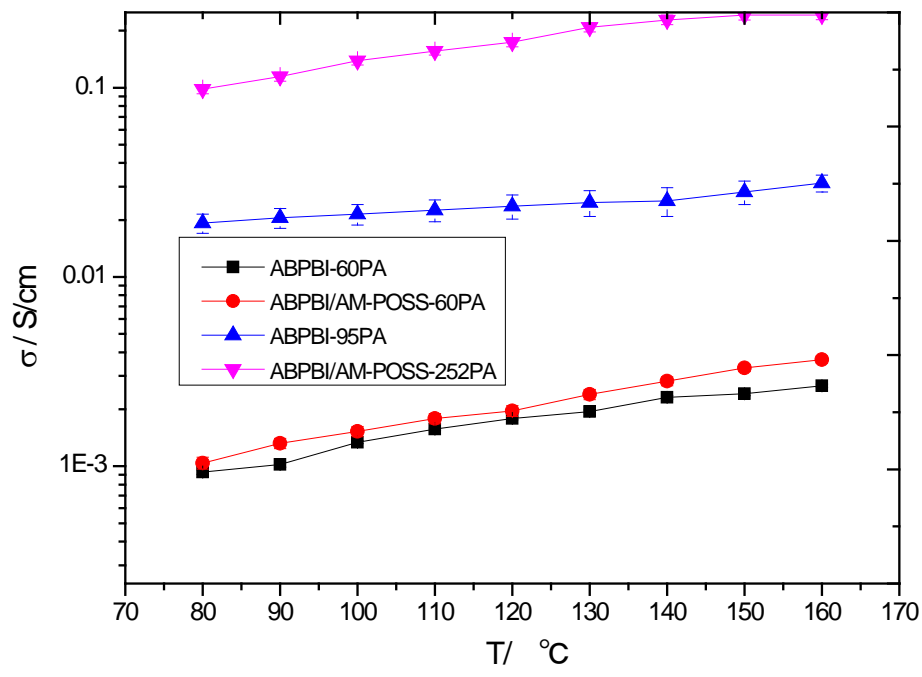


Table 1

Water uptake of $\mathrm{H}_{3} \mathrm{PO}_{4}$ doped ABPBI and ABPBI/AM-POSS membranes

\begin{tabular}{lcc}
\hline \multirow{2}{*}{ Membrane } & \multicolumn{2}{c}{ Water uptake, \% } \\
\cline { 2 - 3 } & Saturated & Ambient atmosphere \\
\hline ABPBI & $31.6 \pm 1.6$ & $23.2 \pm 1.1$ \\
ABPBI-60PA & $34.7 \pm 3.5$ & $13.7 \pm 0.4$ \\
ABPBI-84PA & $53.0 \pm 5.3$ & $15.0 \pm 0.5$ \\
ABPBI/AM-POSS & $106.2 \pm 5.3$ & $32.3 \pm 1.6$ \\
ABPBI/AM-POSS-88PA & $108.0 \pm 5.5$ & $36.1 \pm 0.7$ \\
ABPBI/AM-POSS-153PA & $133.2 \pm 6.5$ & $47.8 \pm 1.0$ \\
ABPBI/AM-POSS-241PA & $153.6 \pm 7.5$ & $58.2 \pm 1.2$ \\
\hline
\end{tabular}

